\title{
Comparative evaluation of retentive strength of polyvinyl siloxane im- pression materials to custom tray using different tray adhesives: An in vitro study
}

\author{
Jinsa P Devassy ${ }^{1}$, Nishna Pradeep ${ }^{2}$, A V Sreekumar ${ }^{2}$, Jimmy George $^{1}$, Jittin James ${ }^{3}$, Jacob George ${ }^{1}$ \\ 1. Department of Prosthodontics, Mar Baselios Dental College, Kerala, India \\ 2. Department of Prosthodontics, Kannur Dental College, Kerala, India \\ 3. Department of Prosthodontics, Indira Gandhi Dental College, Kerala, India
}

\section{Abstract}

The retentive strength of the impression material to the impression tray is an important factor that can affect the quality of the final impression. Separation of the impression from the tray or tearing of the impression while removing from the mouth could be one of the reasons for distortion. It is imperative to know the most effective tray adhesive which can be used with different brands of rubber-based impression material. So, this study was directed to compare the different tray adhesives that can be effectively used in our day-to-day clinical practice.

Keywords: Tray adhesive, Polyvinyl siloxane impression material, Retentive strength.

Citation: Devassy JP, et al. (2020) Comparative evaluation of retentive strength of polyvinyl siloxane impression materials to custom tray using different tray adhesives: An in vitro study. Dentistry 3000. 1:a001 doi:10.5195/d3000.2020.94 Received: March 25, 2020

Accepted: April 25, 2020

Published: May 4, 2020

Copyright: (C2020 Devassy JP, et al. This is an open access article licensed under a Creative Commons Attribution Work 4.0 United States License.

Email: jinsa.pd@gmail.com

\section{Introduction}

The bond strength of an impression material to tray is essential and in case of rubber-based impression materials the retention is mainly achieved via chemical adhesion. To obtain an accurate impression, the impression material must be securely attached to the tray. If the material is not secured to tray firmly while retrieving from the mouth, it will result in improper impression and therefore cause distorted die, wax pattern and casting. [1,2]

The polyvinyl siloxane impression materials are addition reaction silicone elastomers which were first introduced in the 1970s. [3] In the past decade, these materials have occupied a large share of the impression material market. They possess good physical properties and handling characteristics. They have achieved a high level of dentist and patient acceptance as they are clean, odorless and tasteless. [3]

An effective adhesive is especially indicated when the impression material has a high tear resistance, so that it can effectively be removed from undercuts. The chemistry of the adhesives usually are polydimethyl siloxane and ethylsilicate. The adhesive reacts with the surface of the tray material and forms a chemical bond to the tray and to the impression material. It is usually recommended to wait 
for ten to fifteen minutes after application of the adhesive before making the impression. This allows time for the solvent to react with the tray material. Sulong and Setchell [4] demonstrated that roughening the surface of the impression tray will significantly improve the effectiveness of polyvinyl siloxane adhesives.

Impression tray adhesives are applied as a spray, or are manually applied using a brush. Prior to tray loading, the adhesive requires a lengthy drying time. Suggested drying times for adhesives vary widely among manufacturers. Also, adhesive strength of different tray adhesive varies considerably and hence in our clinical practice the knowledge of adhesive strength of various impression materials with certain adhesive is of utmost important for the success of the impression and final result.

Permanent distortion occurs when the impression material does not adhere to the tray. Ideally, the impression material tears instead of undergoing considerable distortion before it is released from the undercut. If the material is not adequately retained in the impression tray when it is removed from the mouth, it may be a potential source of error. The most consistently accurate impression is obtained with the adhesive lined resin custom tray. Each class of elastomeric impression material has its own specific adhesive. Metal and plastic stock trays are used routinely for dental impressions, especially with the putty- wash systems. However, heatacrylic cured trays with an adhesive is recommended for additional silicones [4].

The purpose of this study is to compare the retentive bond strength of the three commonly available brands of poly vinyl siloxane impression materials (Aquasil, Virtual and Express ${ }^{\mathrm{TM}}$ ) to acrylic tray using universal tray adhesive (Zhermarck) and adhesives supplied by the respective manufactures using the universal testing machine.

\section{Materials}

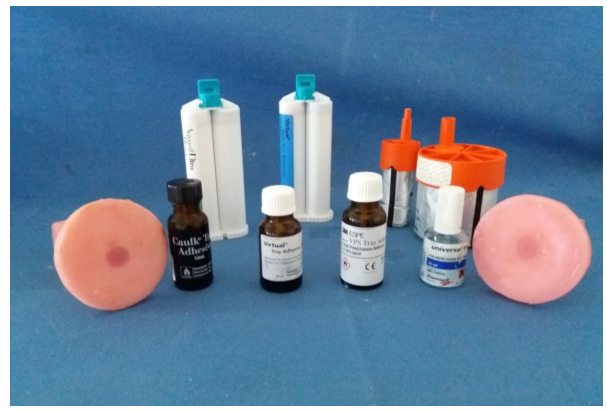

Figure 1. Armamentarium.

Armamentarium (Fig.1):

- Acrylic discs

IMPRESSION MATERIAL:

- Virtual Heavy Body Impression Material-Regular Set (Vivadent)

- Aquasil Ultra Heavy (Dentsply)

- Express $^{\mathrm{TM}}$ XT Penta ${ }^{\mathrm{TM}} \mathrm{H}$ (3M ESPE)

TRAY ADHESIVES:
Brand specific tray adhesives:

- Virtual

- Aquasil

- 3M ESPE

- Universal tray adhesives (Zhermarck)

\section{Methods}

The polyvinyl siloxane heavy body impression materials selected were Aquasil, Virtual, Express $^{\mathrm{TM}}$ and these formed the groups I, II and III.

Group I: Aquasil impression material.

Group II: Virtual impression material.

Group III: Express ${ }^{\mathrm{TM}}$ impression material.

The tray adhesives selected were universal tray adhesives (Zhermarck) \& adhesives of respective impression materials. The main groups were further subdivided based on the adhesives used. Total sample size used were 135.

\section{The procedures were divided into five steps:}

Step 1: Preparation of the acrylic discs.

Step 2: Application of adhesives.

Step 3: Placement of disc on universal testing machine.

Step 4: Injection of heavy body material to acrylic disc.

Step 5: Checking the retentive strength of impression material. 


\section{Step 1: Preparation of acrylic disc}

For preparing the acrylic disc a wax pattern of diameter of $64 \mathrm{~mm}$ and height $9 \mathrm{~mm}$ was made using modeling wax. Simultaneously another cylindrical wax pattern of diameter $28 \mathrm{~mm}$ height and $12 \mathrm{~mm}$ diameter was made for perpendicular shaft. The wax pattern was invested and acrylisation was done using compression molding technique. Then heat cured acrylic disc and shaft thus obtained were finished and smoothed using 320-grit silicone-carbide paper to standardize surface roughness. The heat cured acrylic cylinder shaft was attached to center of the heat cure acrylic disc using self-cure acrylic. Three pairs of same kind were fabricated for convenience purpose. For each time after the loading, ethanol was used for cleaning the acrylic disc as recommended by the manufacturers of tray adhesives.

\section{Step 2: Application of adhe- sives on disc}

Based on the adhesives used the main group was divided into subdivisions $A, B$ and $C$ [Table 1].

Subdivision A of main Groups I, II and III was kept as control group. The adhesive was not applied to all the samples tested in this subdivision.

In subdivision B of Group I, Caulk tray adhesives [brand specific] was applied on the disc. The adhesive was applied using a brush as thin as possible [Fig.2]. Only a single coat was applied and it allowed to dry for 5 minutes*.

In Group II subdivision B, Virtual tray adhesives was applied using brush as thin as possible and allowed to dry for 3 minutes*.

In Group III subdivison B, 3M ESPE tray adhesive was applied as thin as possible and allowed to dry for 5 minutes*.

In subdivision C of all Groups, the universal tray adhesive (Zhermarck) was applied on the acrylic disc in the same manner. It was allowed to dry for 2 minutes*.

*Time as recommended by the manufacturer.

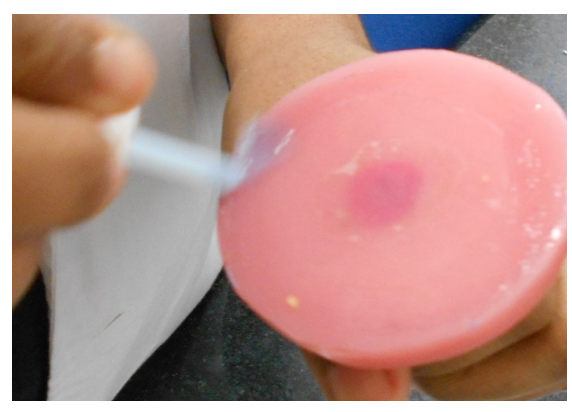

Figure 2. Application of adhesives.

\section{Placement of disc on universal testing machine}

\section{$\underline{\text { Universal testing machine }}$}

Universal testing machine (model LR5K plus) consists of upper compartment and lower compartment. It is an automatic computerized machine for high accuracy load measurements with LCD display [Fig. 3]. It is also connected to a personal computer for programming and data collection. It is operated using software called Nexygen. Once loaded this machine itself will automatically align the disc for measurements.

After the application of tray adhesives, the acrylic disc was placed on lower compartment and another acrylic disc was placed on upper compartment. Then ensured the acrylic disc aligned properly.

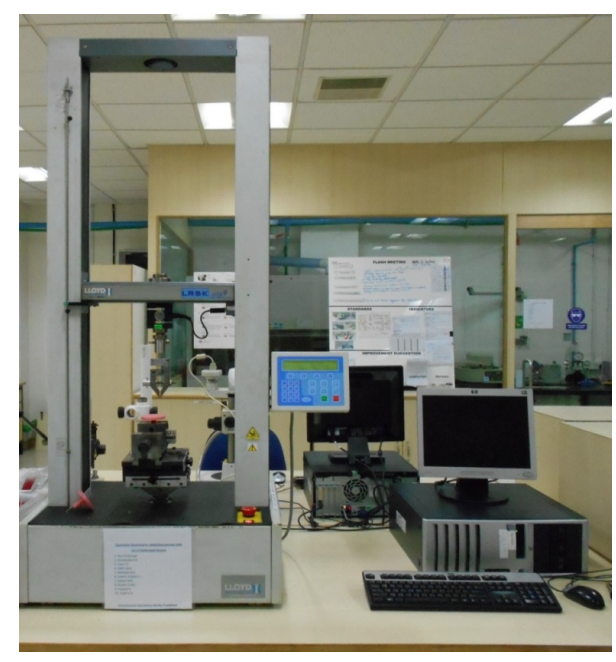

Figure 3. Universal Testing Machine [LR5K PLUS].

Injection of heavy body material

Heavy body material was injected [Fig. 4] on the lower disc and then upper disc lowered until a space of $4 \mathrm{~mm}$ [Fig. 5]. Care was taken to ensure that the heavy body material completely occupied in this $4 \mathrm{~mm}$ space between the 
acrylic discs [Fig. 6]. Impression material used was different for each group [Table 1].

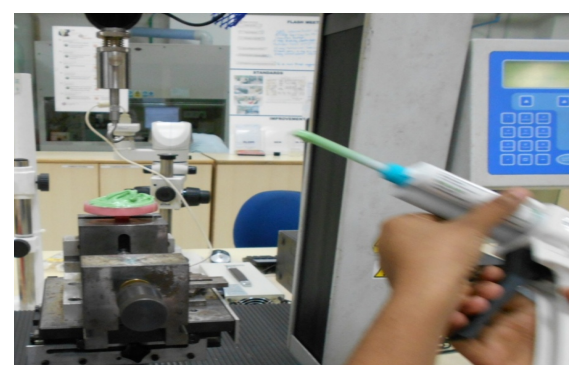

Figure 4. Injection of heavy body material.

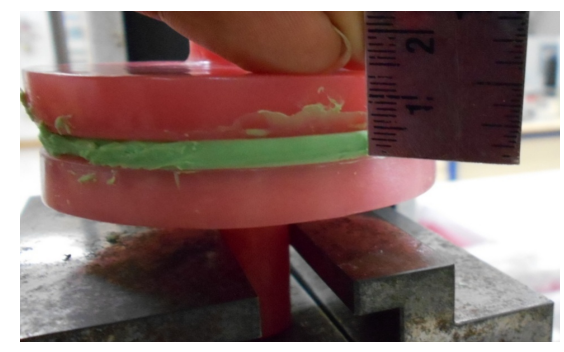

Figure 5. Heavy body material between the acrylic discs.

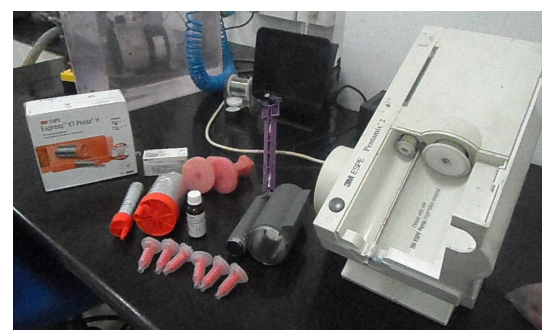

Figure 6. Penta mix dispenser.

In Group I the Aquasil impression material injected using mixing gun and the material was allowed to polymerize for 5 minutes*.

In Group II, Virtual impression material dispensed using mixing gun and allowed to set for 4.30 minutes*.
Table 1. Grouping of selected impression materials with its subdivisions based on tray adhesives used.

\begin{tabular}{llll}
\hline & SUB DIV A & SUB DIV B & SUB DIV C \\
GROUP I & WITHOUT TRAY ADHESIVE & CAULK TRAY ADHESIVE & ZHERMARCK \\
AQUASIL [45 samples] & 15 samples & 15 samples & TRAY ADHESIVE \\
& & & 15 samples \\
\hline & SUB DIV A & SUB DIV B & SUB DIV C \\
GROUP II & WITHOUT TRAY ADHESIVE & VIRTUAL TRAY ADHESIVE & ZHERMARCK \\
VIRTUAL [45 samples] & 15 samples & 15 samples & TRAY ADHESIVE \\
& & & 15 samples \\
& & & \\
\hline & SUB DIV A & SUB DIV B & SUB DIV C \\
GROUP III & WITHOUT TRAY ADHESIVE & 3M ESPE TRAY ADHESIVE & ZHERMARCK \\
EXPRESS TM [45 samples] & 15 samples & 15 samples & TRAY ADHESIVE \\
& & & 15 samples
\end{tabular}

In case of Group III for Express ${ }^{\mathrm{TM}}$, pentamix dispenser [Fig. 6] was used and allowed to set for 3.30 minutes*

* Time as recommended by the manufacturer.

\section{Checking the retentive strength}

The test specimens were tested in tensile mode at a cross- head speed of $6 \mathrm{~mm} / \mathrm{min}$ until separation failure [Fig. 7] occurred and maximum force of separation is automatically recorded and saved to the computer both numerically and graphically [Fig.8].

The study was conducted on remaining samples in a similar manner and results were statistically analyzed using One Way ANOVA and Tukey Post-Hoc test.

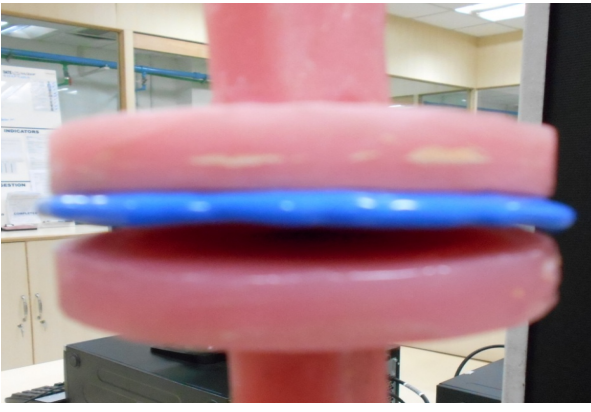

Figure 7. Impression material separation at maximum load.

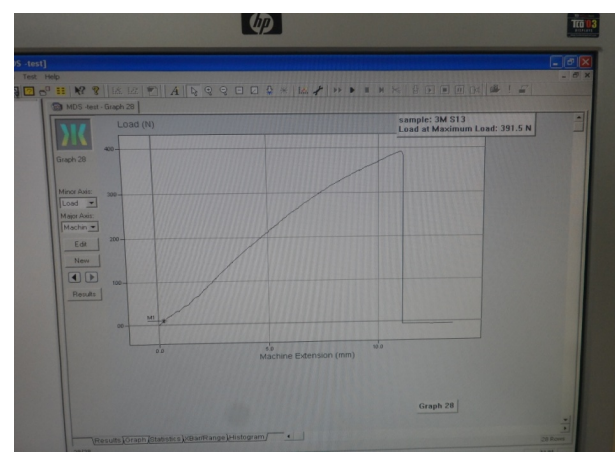

Figure 8. Computer generated graph according to the maximum force of separation failure. 
Table 2. Maximum force of separation failure in group I in Newton [N]

\begin{tabular}{|c|c|c|c|c|c|c|c|c|c|c|c|c|c|c|c|c|}
\hline \multirow[b]{2}{*}{ Material } & \multirow[b]{2}{*}{ Test } & \multicolumn{15}{|c|}{ Tests Results in $(\mathrm{N})$} \\
\hline & & 1 & 2 & 3 & 4 & 5 & 6 & 7 & 8 & 9 & 10 & 11 & 12 & 13 & 14 & 15 \\
\hline \multirow{3}{*}{$\begin{array}{l}\text { Group I- } \\
\text { Aquasil }\end{array}$} & $\begin{array}{l}\text { Aquasil without tray } \\
\text { adhesive, } \\
\text { Sub division A }\end{array}$ & 230,4 & 242.7 & 269.3 & 234.8 & 238.6 & 250.6 & 286.1 & 232.4 & 241,4 & 250.5 & 260,5 & 238.0 & 261.2 & 258.4 & \begin{tabular}{l|l}
4 & 264,6
\end{tabular} \\
\hline & $\begin{array}{l}\text { Aquasil with brand } \\
\text { specific tray adhesive, } \\
\text { Sub division B }\end{array}$ & 696.8 & 631.6 & 745.5 & 687.4 & 698.1 & 717.6 & 689.3 & 714.5 & 726.4 & 701.2 & 697.4 & 697.3 & 701.3 & 727.4 & $\begin{array}{l}4731.9 \\
\end{array}$ \\
\hline & $\begin{array}{l}\text { Aquasil with universal } \\
\text { tray adhesive, } \\
\text { Sub division C }\end{array}$ & 892.1 & 889.3 & 890.3 & 860.0 & 900.1 & 895.3 & 896.7 & 874.6 & 892.4 & 865.2 & 893.0 & 891.1 & 901.1 & 884.5 & 887.3 \\
\hline
\end{tabular}

Table 3. Maximum force of separation failure in group II in Newton [N]

\begin{tabular}{|c|c|c|c|c|c|c|c|c|c|c|c|c|c|c|c|c|}
\hline \multirow[b]{2}{*}{ Material } & \multirow[b]{2}{*}{ Test } & \multicolumn{15}{|c|}{ Tests Results in (N) } \\
\hline & & 1 & 2 & 3 & 4 & 5 & 6 & 7 & 8 & 9 & 10 & 11 & 12 & 13 & 14 & 15 \\
\hline \multirow{3}{*}{$\begin{array}{l}\text { Group II - } \\
\text { Virtual }\end{array}$} & $\begin{array}{l}\text { Virtual without tray } \\
\text { adhesive, } \\
\text { Sub division A }\end{array}$ & 504.5 & 351.3 & 542.2 & 445.0 & 501.4 & 526.7 & 538.6 & 528.5 & 514.9 & 536.4 & 516.4 & 498.4 & 484.2 & 509.7 & 525.1 \\
\hline & $\begin{array}{l}\text { Virtual with brand tray } \\
\text { adhesive, } \\
\text { Sub division B }\end{array}$ & 782.8 & 3836.7 & 848.8 & 789.1 & 800.4 & 793.6 & 806.4 & 818.4 & 801.2 & 817.6 & 784.9 & 768.9 & 794.8 & 806.1 & 826.0 \\
\hline & $\begin{array}{l}\text { Virtual with universal } \\
\text { tray adhesive, } \\
\text { Sub division C }\end{array}$ & 900.1 & 894.3 & 900.4 & 894.0 & 886.2 & 900.4 & 889.4 & 878.3 & 899.8 & 879.6 & 883.8 & 875.0 & 894.2 & 894.1 & 900.2 \\
\hline
\end{tabular}

Table 4. Maximum force of separation failure in group III in Newton [N]

\begin{tabular}{|c|c|c|c|c|c|c|c|c|c|c|c|c|c|c|c|c|}
\hline \multirow[b]{2}{*}{ Material } & \multirow[b]{2}{*}{ Test } & \multicolumn{15}{|c|}{ Tests Results in (N) } \\
\hline & & 1 & 2 & 3 & 4 & 5 & 6 & 7 & 8 & 9 & 10 & 11 & 12 & 13 & 14 & 15 \\
\hline \multirow{3}{*}{$\begin{array}{l}\text { Group III } \\
\text { Express }\end{array}$} & $\begin{array}{l}\text { Express }^{\mathrm{TM}} \text { without tray } \\
\text { adhesive, } \\
\text { Sub division } A\end{array}$ & 330.0 & 360.5 & 346.2 & 337.4 & 367.5 & 368.9 & 388.1 & 324.8 & 346.7 & $7 \mid 345.7$ & 324.5 & 342.6 & 391.5 & 347.5 & 5353.2 \\
\hline & $\begin{array}{l}\text { Express }^{\mathrm{TM}}{ }^{\mathrm{M}} \text { with brand } \\
\text { tray adhesive, } \\
\text { Sub division B } \\
\end{array}$ & 496.1 & 514.8 & 512.4 & 491.0 & 516.9 & 532.0 & 521.4 & 516.4 & 514.3 & 3501.0 & 520.5 & 498.5 & 511.2 & 498.6 & 6523.9 \\
\hline & $\begin{array}{l}\text { Express }^{\mathrm{TM}} \text { with universal } \\
\text { tray adhesive, } \\
\text { Sub division C }\end{array}$ & 630.8 & 647.9 & 756.3 & 748.2 & 723.7 & 687.1 & 684.0 & 696.7 & 714.7 & 7697.1 & 749.5 & 739.0 & 711.9 & 687.2 & 2781.8 \\
\hline
\end{tabular}

\section{Results}

On comparison Aquasil with universal tray adhesive showed greater retentive strength than Aquasil with brand specific tray adhesive and Aquasil without tray adhesive [Table 2].

On comparison Virtual with universal tray adhesive showed greater retentive strength than Virtual with brand specific tray adhesive and Virtual without tray adhesive [Table 3].

On comparison Express ${ }^{\mathrm{TM}}$ with universal tray adhesive showed greater retentive strength than Express $^{\mathrm{TM}}$ with brand specific tray adhesive and Express ${ }^{\mathrm{TM}}$ without tray adhesive [Table 4].

On applying One Way ANOVA, it was found that there was significant difference [p-value $<0.001]$ in mean retentive strength between the study subgroups. The mean value of the retentive strength is highest for Virtual with universal tray adhesive and lowest for Aquasil without tray adhesive [Table 5].

Table 6 shows the summary of interactions of sub groups with each other. Comparing subdivisions $A, B$ and $C$ of Group I, II and III, the subdivision $\mathrm{C}$ showed the greatest retentive values than subdivision $B$ and subdivision $\mathrm{A}$. When comparing Group I, II, and III, the Group II showed the greatest retentive values than Group I and Group III. 
Table 5. One way anova test to compare the retentive strength of the subdivisions.

\begin{tabular}{|c|c|c|c|c|c|c|c|c|c|}
\hline & & & $\begin{array}{c}\text { Number of } \\
\text { values }\end{array}$ & Mean & Std. Deviation & $\begin{array}{c}\text { Lower } 95 \% \\
\mathrm{Cl}\end{array}$ & $\begin{array}{c}\text { Upper } 95 \% \\
\mathrm{Cl}\end{array}$ & $\mathbf{F}$ & $p$ value \\
\hline \multirow{3}{*}{ Grp I } & Subdiv A & $\begin{array}{c}\text { Aquasil without tray adhe- } \\
\text { sive }\end{array}$ & 15 & 250.6 & 15.85 & 241.9 & 259.4 & \multirow{9}{*}{1166} & \multirow{9}{*}{$<0.001$} \\
\hline & Subdiv B & $\begin{array}{c}\text { Aquasil brand specific tray } \\
\text { adhesive }\end{array}$ & 15 & 704.2 & 26.41 & 689.6 & 718.9 & & \\
\hline & Subdiv C & $\begin{array}{c}\text { Aquasil universal tray ad- } \\
\text { hesive }\end{array}$ & 15 & 887.5 & 12 & 880.9 & 894.2 & & \\
\hline \multirow{3}{*}{ Grp II } & Subdiv A & $\begin{array}{l}\text { Virtual without tray adhe- } \\
\text { sive }\end{array}$ & 15 & 501.6 & 48.34 & 474.8 & 528.3 & & \\
\hline & Subdiv B & Virtual brand tray adhesive & 15 & 805 & 21.43 & 793.2 & 816.9 & & \\
\hline & Subdiv C & $\begin{array}{l}\text { Virtual universal tray adhe- } \\
\text { sive }\end{array}$ & 15 & 891.3 & 8.801 & 886.4 & 896.2 & & \\
\hline \multirow{3}{*}{ Grp III } & Subdiv A & $\begin{array}{c}\text { Express tm without tray } \\
\text { adhesive }\end{array}$ & 15 & 351.7 & 20.47 & 340.3 & 363 & & \\
\hline & Subdiv B & $\begin{array}{c}\text { Express tm brand tray ad- } \\
\text { hesive }\end{array}$ & 15 & 511.3 & 11.74 & 504.8 & 517.8 & & \\
\hline & Subdiv C & $\begin{array}{l}\text { Express tm universal tray } \\
\text { adhesive }\end{array}$ & 15 & 710.4 & 41.03 & 687.7 & 733.1 & & \\
\hline
\end{tabular}

\section{Discussion}

The impression adhesives used for silicone impression materials contain polydimethyl-siloxane or a similar reactive silicone, and ethyl silicate. Polymethylsiloxane of adhesives bonds to the silicone impression material whereas ethylsilicate forms a hydrated silica that bonds to the impression tray material physically. The volatile solvent in the form of ethyl acetate reacts with the acrylic tray material to create microporosities on the tray material so that the adhesive physically and mechanically bonds with it.

Sulong and Setchell [3] studied the properties of tray adhesives of addition polymerizing silicones to impression tray materials. They 
reported that acrylic resin trays roughened with eighty grit silicone-carbide created highest strength and they also concluded that adhesives did not adhere well to chromium plated metal or plastic stock tray material.

Samman [5] studied about impression tray adhesives and reported that tray adhesives definitely

Table 6. A cross table showing interaction of subgroups with each other by post-hoc tukey test $\mathbf{p}$ value. (*Significant $\mathbf{P}$ values).

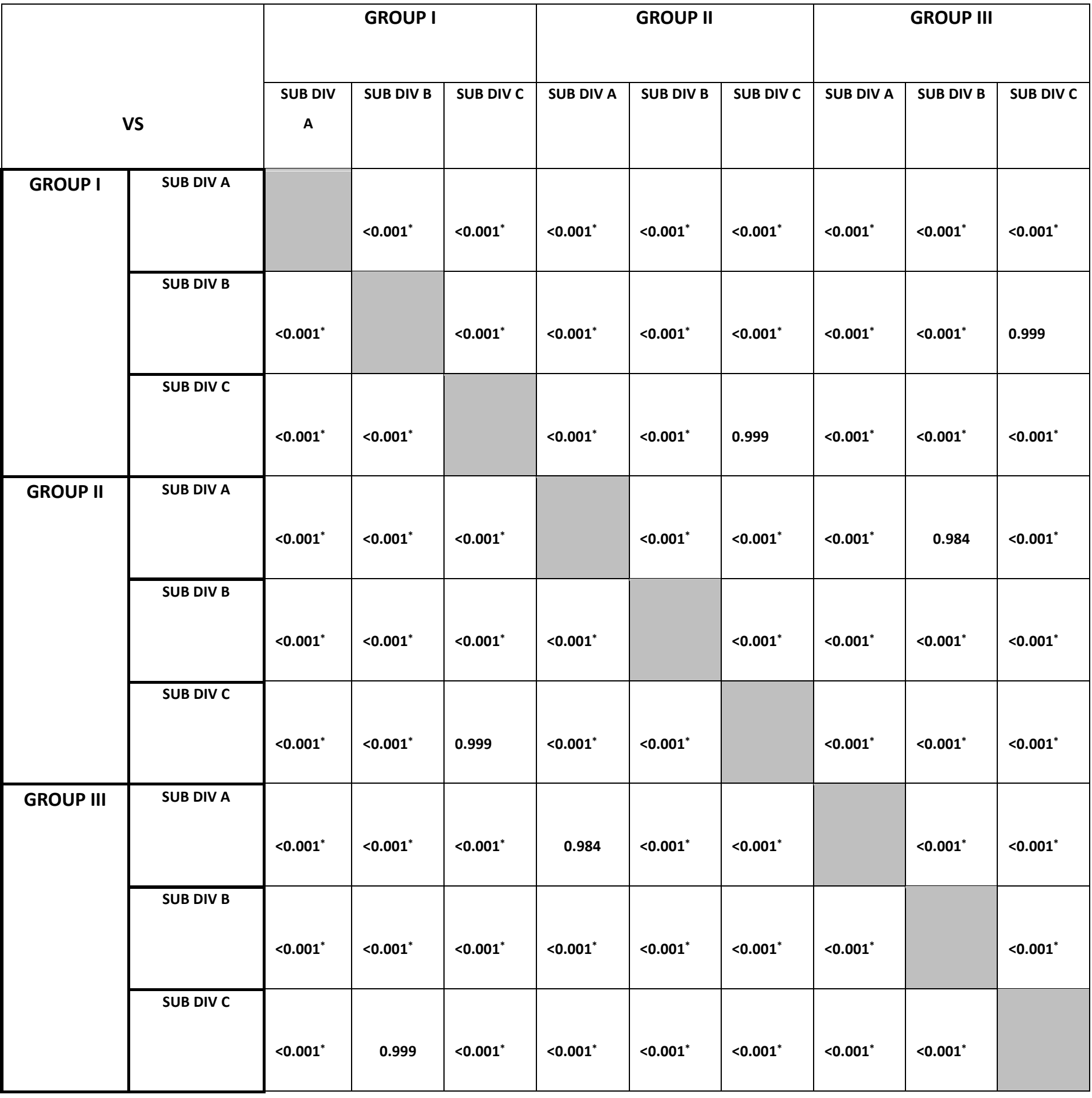


Tjan and Sung [6] reported the significance of tray adhesives in case where the impressions were poured repeatedly, to minimize accidental separation of the impression from the tray.

Though manufacturers have come out with its own tray adhesives for particular rubber-based impression materials, previous literature $[1,7]$ has reported that it might not be the best. Paint-on adhesive on medium body VPS is found to be effective. [5,7]

Considering the above facts, the study was done to compare the effectiveness of the universal tray adhesive, Zhermarck with the three commonly available medium consistency VPS impression materials, Aquasil, Virtual and Express $^{\top \mathrm{TM}}$ with their respective tray adhesives, Caulk, Virtual and 3M ESPE.

Among the different groups studied, heavy body impression material with universal tray adhesives [subdivision C] showed the highest value. In subdivision $\mathrm{C}$, the tray adhesive used was Zhermarck tray adhesive. The results of the study agree with the findings of study done by Land ${ }^{7}$ et al. and Ashiwini et al. [1] In their study, they evaluated the bond strength of the three polyvinyl siloxane materials with a methacyrlate autopolymerizing and light polymerizing tray material, using the adhesives recommended by the manufactures of the impression materials and two universal adhesives (paint on and spray on). They reached the conclusion that paint on universal tray adhesives offers the advantage of providing equal or superior adhesive bond strength for the three VPS impression materials to the autopolymerizing and light polymerizing tray materials tested, compared to the manufactures recommended adhesives. When comparing subdivision $A$ [without tray adhesives] of all groups, group II [Virtual heavy body impression material] showed the greatest bond strength and it is statistically significant [Table 6 , Graph 1]. Without using any tray adhesives retentive bond strength of Virtual heavy body impression material to acrylic resin tray material which was roughened by 320 grit silicon carbide was comparatively higher than group I [Aquasil heavy body impression material]

\section{Graph 1. Bar diagram showing comparison of groups and subdivisions.}

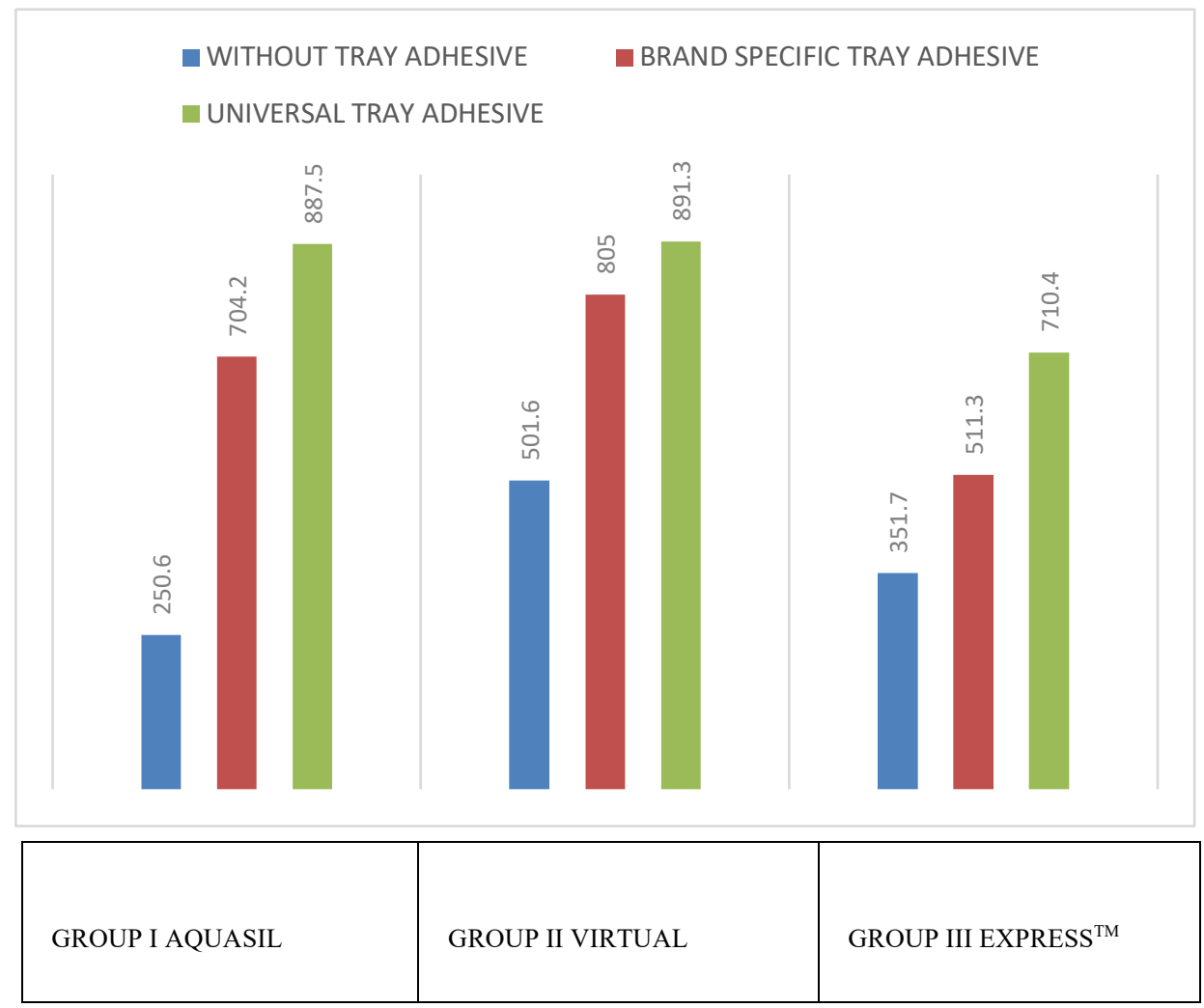

and group III [Express ${ }^{\mathrm{TM}}$ heavy body impression material].

When comparing the subdivision B [brand specific] of all groups, group II [Virtual heavy body impression material] showed the greatest bond strength than group I Aquasil heavy body impression material and Group III Express ${ }^{\mathrm{TM}}$ heavy body impression material [Table 6, Graph 1 ]. When comparing the subdivision $\mathrm{C}$ of all groups, there is no significant difference observed [Table 6]. As already stated, on comparison of the subdivisions $\mathrm{A}, \mathrm{B}$ and $\mathrm{C}$, the subdivision $C$ [with universal tray adhesives] showed the greatest bond strength and is statistically significant [Table 6].

Variations in bond strength of impression material, adhesive agent 
and custom tray material combination is related to 1 . The chemistry of the adhesive agents 2 . The surface chemistry of the resin tray material. [8]

The significantly greater bond strengths of Zhermarck universal tray adhesive were probably attributable to the higher adhesive capability of these adhesives. The adhesion of the tray adhesives is achieved because of chemical adhesion between the impression material and methyl methacrylate tray material. Upon application of the tray adhesive, the carrier solvent present in the adhesive causes swelling of the outermost surface of the tray, thereby allowing the adhesive to penetrate and interact intimately with the impression material. The solvent then evaporates, leaving the entire tray surface covered with the adhesive, which is retained within the molecular network of the impression material.

The retention of impression materials to acrylic resin tray material ultimately depends on the ability of the solvent in the adhesive to dissolve the resin tray material. Thus solvent evaporation is considered as the "setting" of the adhesive and is dependent on time, temperature and relative humidity [9]. It is generally recommended to wait for a few minutes after application of the adhesive before making the impression. This allows time for the solvent to react with the tray material.
Therefore, in this present study, the better adhesive bond strength of Zhermarck universal tray adhesive in comparison with brand specific tray adhesives may be attributed to the difference in the solubility of the tray material by the solvent present in the tray adhesive.

From the results obtained in this study, Zhermarck universal tray adhesive with addition silicone impression material could be recommended as an ideal tray adhesiveimpression material combination using acrylic resin tray material. When comparing among the heavy body impression materials selected, Aquasil, Virtual and Express $^{T M}$, the Virtual heavy body impression material showed the greatest retentive strength to custom tray with both brand specific tray adhesive and universal tray adhesive.

\section{Clinical Implications}

From the results of this study, it can be concluded that the universal tray adhesive can be used in our clinical practice with most of the elastomeric impression materials to attain maximum results without the need of the adhesive supplied by the respective manufacturer.

\section{Acknowledgements}

Mr. Binish Jacob, Mr. Arun, Assistant Managers and Mr. Abilash, engineer in US based amphenol fci-oen Connentors Ernakulam, India.
Dr. Sreekanth, Research

Investigator, Manipal Institute of Medical Science, India.

Dr. Imad Muhammed Ismail, Assistant Professor in Kannur Dental College, India.

Dr. Shahanaz Hamza, Dr. Harsha Gangadharan, Dr. Navaz, House Surgeons Anjarakandy Dental College, India.

Mr. Satheesh, Lab Assistant in Kannur Dental College, India.

\section{References}

1. The bond strength of different tray adhesives on vinyl polysiloxane to two tray materials: an in vitro study. Ashwini BL, Manjunath S, Mathew KX. J Indian Prosthodont Soc. 2014 Mar;14(1):29-37. doi: 10.1007/s13191-012-0184$z$.

2. Considerations for adhesion of impression materials to impression trays. Bomberg TJ, Goldfogel MH, Hoffman W Jr, Bomberg SE. J Prosthet Dent. 1988 Dec;60(6):681-4.

3. Polyvinyl siloxane impression materials: an update on clinical use. Mandikos MN. Aust Dent J. 1998 Dec;43(6):428-34.

4. Properties of the tray adhesive of an addition polymerizing silicone to impression tray materials. Sulong MZ, Setchell DJ. J Prosthet Dent. 1991 Dec;66(6):7437. 
5. A study of impression tray adhesives. Samman

JM, Fletcher A. Quintessence Int. 1985

Apr;16(4):305-9.

6. Comparing effects of tray treatment on the accuracy of dies. Tjan AH, Whang SB. J Prosthet Dent. 1987 Aug;58(2):175-8.

7. The effect of different adhesives on vinyl polysiloxane bond strength to two tray materials. Peregrina A, Land MF, Wandling C, Johnston WM. J Prosthet Dent. 2005 Sep;94(3):20913.

8. Bond strength of two nonaqueous elastomeric impression materials bonded to two thermoplastic resin tray materials. Payne JA, Pereira BP. J Prosthet Dent. 1995 Dec;74(6):563-8.

9. Retention strength of impression materials to a tray material using different adhesive methods: an in vitro study. Marafie $\mathrm{Y}$, Looney S, Nelson S, Chan D, Browning W, Rueggeberg F. J Prosthet Dent. 2008 Dec;100(6):432-40. doi: 10.1016/S00223913(08)60260-7. 